\title{
Mechanically activated mine tailings for use as supplementary cementitious materials
}

\author{
Sivakumar Ramanathan ${ }^{1}$, Priyadharshini Perumal ${ }^{2}$, Mirja Illikainen² $^{2}$ Prannoy Suraneni ${ }^{1 *}$ \\ 1 Department of Civil, Architectural, and Environmental Engineering, University of Miami, Coral Gables, FL 33416, USA \\ 2 Faculty of Technology, Fiber and Particle Engineering Research Unit, PO Box 4300, University of Oulu, Oulu 90014, Finland
}

Received: 17 April 2021 / Accepted: 01 July 2021 / Published online: 16 July 2021

(C) The Author(s) 2021. This article is published with open access and licensed under a Creative Commons Attribution 4.0 International License.

\begin{abstract}
Two mine tailings were evaluated for their potential as supplementary cementitious materials. The mine tailings were milled using two different methods - ball milling for 30 minutes and disc milling for durations ranging from 1 to 15 minutes. The modified $\mathrm{R}^{3}$ test was carried out on the mine tailings to quantify their reactivity. The reactivity of the disc milled tailings is greater than those of the ball milled tailings. Strong correlations are obtained between milling duration, median particle size, amorphous content, dissolved aluminum and silicon, and reactivity of the mine tailings. Fineness and the amorphous content increase appreciably in the first 8 minutes of disc milling but not beyond that duration. The reactivity increases significantly beyond a certain threshold fineness and amorphous content. Cementitious pastes were prepared at $30 \%$ supplementary cementitious materials replacement level at a water-to-cementitious materials ratio of 0.40 . No negative effects of the mine tailings were observed at early ages in cement pastes based on isothermal calorimetry and thermogravimetric analysis, demonstrating the potential for these materials to be used as supplementary cementitious materials.
\end{abstract}

Keywords: Mine tailings; Activation; Reactivity; Supplementary cementitious materials

\section{Introduction}

Rising shortfalls in the supply of conventional supplementary cementitious materials (SCMs) have resulted in a need to explore alternative SCMs [1,2]. Several alternative SCMs, including steel slags, ponded and reclaimed fly ashes, and zeolites have been studied in literature [3-11]. These materials are largely waste materials of negligible economic value and/or side stream products, which if not upcycled or utilized, would be landfilled or ponded, resulting in negative environmental consequences [12-14]. Mine tailings are a potential alternative SCM source, available in large quantities worldwide. Mine tailings are available in the form of waste slurry after extracting economically viable ores from them [15]. Because ore extraction is a ubiquitous activity, vast reserves of these tailings are available, and amounts are projected to increase with increasing mining activity. Studies have explored utilizing mine tailings as SCMs, alternative aggregates, non-structural construction materials, and backfill applications [15-19]. A recent study was undertaken to explore the possibility of alkali activating processed mine tailings. Mechanically activating mine tailings resulted in an increase in fineness and amorphous content and an increase in compressive strength of the resulting alkali activated binders [17]. As the amorphous content and fineness both increase due to milling, processed mine tailings could also be used as SCMs.

Only a few systematic studies exist regarding the utilization of mine tailings as SCMs in concrete due to variations in composition and perceived low reactivity $[15,16,19,20]$. A replacement level of $10-20 \%$ has generally been recommended to avoid negative effects on compressive strength $[19,20]$. Strategic use of pretreatment methods that have an impact on the behavior of mine tailings in concrete can improve the long-term benefits associated with the use of mine tailings [19]. No studies exist that have directly quantified the reactivity of mine tailings. Generalizing the behavior of mine tailings is complex on account of different sources and ores extracted leading to considerable differences in mine tailing properties [15]. In this study, we explore the use of processed mine tailings as SCMs with a focus on milling-induced changes in mine tailing properties and their reactivity.

For a material to be a feasible SCM, SCM nature, SCM reactivity, and effects of the SCM in cementitious mixtures must be understood [21-23]. SCM reactivity depends on the type and amount of the amorphous calcium aluminosilicate phases, bulk chemical composition, SCM fineness, and SCM replacement level, among other factors [2,21-25]. At least for some completely crystalline materials, beneficiation using

\footnotetext{
* Corresponding author: Prannoy Suraneni, E-mail: suranenip@miami.edu
} 
mechanochemical activation does not appear to be very effective [25]. On the other hand, materials with "low" amorphous contents could potentially be mechanochemically activated on account of increased disorder, defects, and localized surface amorphization induced by milling. However, the activation mechanisms and subsequent behavior of low amorphous content aluminosilicates, threshold levels for activation, and processing-reactivity relationships are not well studied or understood. Other beneficiation techniques such as thermal activation (calcination), chemical activation (for example by using certain inorganic additives), and hybrid activation techniques are also available and could be used to increase the reactivity of materials with low amorphous content [26].

SCM reactivity has traditionally been evaluated using tests such as the strength activity index test, Chapelle test, Frattini test, and the lime reactivity tests, which are flawed for various reasons [27-33]. The recently developed $R^{3}$ test and its variant, the modified $\mathrm{R}^{3}$ test, have shown greater accuracy in distinguishing between reactive and inert SCMs $[23,34]$. The modified $\mathrm{R}^{3}$ test, which we have extensively studied [21-23], utilizes two measures of SCM reactivity - heat release and calcium hydroxide consumption to classify SCMs into inert, pozzolanic, or latent hydraulic materials. The modified $\mathrm{R}^{3}$ test can be utilized as a rapid screening test for potential SCMs before carrying out more detailed evaluations of their effects on concrete [35].

In the current study, processed (dried and milled) mine tailings from two sources in Finland were evaluated using the modified $\mathrm{R}^{3}$ test to directly quantify their reactivity. The effects of two different milling methods (ball milling and disc milling) on the physical and chemical properties and reactivity of the mine tailings were quantified. Potential negative effects of mine tailings on early age hydration of cementitious systems were evaluated by replacing a portion of OPC with the milled mine tailings.

\section{Materials and methods}

Mine tailings were obtained from two different sources: nickel and copper mines (denoted NiCu tailings) and quartz (denoted Qtz tailings) from Finland. Other work has evaluated the potential of alkali activation for similar disc milled mine tailings [17]. The mine tailing materials received as-is were rather coarse ( $0.1 \mathrm{~mm}$ to $2 \mathrm{~mm}$ in particle size) and had high moisture content. They were dried for 24 hours at $100{ }^{\circ} \mathrm{C}$ to remove the moisture. The chemical composition of the mine tailings prior to milling was measured using a calibrated X-ray fluorescence device and is shown in Table 1. To obtain milled samples, the dried tailings were milled using two different methods - ball milled for 30 minutes (labelled NiCu-B-30 and Qtz-B-30) using a laboratory ball mill at $450 \mathrm{rpm}$ and disc milled for different durations ranging from 1-15 minutes (labelled NiCu-D-x and Qtz-D-x, where $x$ is the duration of milling in minutes) using a disc mill at $1500 \mathrm{rpm}$. In the ball mill, feed material is milled to the desired fineness in a cylindrical drum with hardened abrasion resistant steel balls as milling media. In the laboratory disc mill, the feed material is pulverized in between discs at high intensity. Ball milling is cheaper and consumes lesser energy compared to disc milling. The median particle size $\left(d_{50}\right)$ values of the milled mine tailings, measured by laser diffraction, are shown in Fig. 1a. To evaluate the early-age hydration behavior of cementitious mixtures, a commercially available Type I/II OPC was used, whose chemical composition is shown in Table 1. The values of $d_{10}, d_{50}$, and $d_{90}$ are $2.2 \mu \mathrm{m}, 16.2 \mu \mathrm{m}$, and 42.7 $\mu \mathrm{m}$ for the OPC and vary based on milling duration for the mine tailings. Both mine tailings had LOI less than $1 \%$. Since we are using a closed system, it is assumed that the bulk chemical composition of the milled tailings is the same as that of the unmilled tailings.

Table 1. Chemical composition of the mine tailings [17]

\begin{tabular}{|l|l|l|l|}
\hline Oxide (\%) & OPC & NiCu tailings & Qtz tailings \\
\hline $\mathrm{Na}_{2} \mathrm{O}$ & 0.15 & 0.40 & 1.20 \\
\hline $\mathrm{MgO}$ & 1.31 & 22.90 & 4.90 \\
\hline $\mathrm{Al}_{2} \mathrm{O}_{3}$ & 4.88 & 2.30 & 22.10 \\
\hline $\mathrm{SiO}_{2}$ & 21.78 & 47.00 & 45.80 \\
\hline $\mathrm{SO}_{3}$ & 1.74 & 0.30 & 0.00 \\
\hline $\mathrm{K}_{2} \mathrm{O}$ & 0.31 & 0.10 & 0.30 \\
\hline $\mathrm{CaO}$ & 63.76 & 12.80 & 16.50 \\
\hline $\mathrm{Fe}_{2} \mathrm{O}_{3}$ & 2.96 & 13.30 & 8.60 \\
\hline
\end{tabular}

\subsection{Quantitative X-ray diffraction}

Quantitative X-ray diffraction (QXRD) of the mine tailings was obtained using a XRD device with Co Ka radiation. Rutile was used as an internal standard ( $10 \%$ by weight) to quantify the phases present. A known quantity of rutile was weighed and mixed with the milled tailings and the mixture was carefully homogenized using mortar and pestle. A step interval of $0.02^{\circ}$ per step, a scan rate of $3^{\circ} / \mathrm{min}$ from $5-120^{\circ} 2 \theta$ were utilized for all mine tailings. Phases were quantified using Rietveld analysis using X'pert HighScore Plus analytical software [17]

\subsection{Dissolution tests}

The dissolution behavior of the mine tailings in an alkaline medium was studied by mixing $0.5 \mathrm{~g}$ of the mine tailings in 20 $\mathrm{g}$ of $6 \mathrm{M} \mathrm{NaOH}$. The mixture was stirred using a shaker at 150 rpm for 24 hours at room temperature. The solution was filtered through a $0.45 \mu \mathrm{m}$ pore size polypropylene membrane. The $\mathrm{pH}$ of the filtrate was reduced to less than 2 using a $6 \mathrm{M}$ nitric acid solution to prevent precipitation. Inductively couple plasma optical emission spectroscopy (ICP$\mathrm{OES}$ ) was conducted on the filtrate and the elemental concentrations of $\mathrm{Al}, \mathrm{Si}, \mathrm{Ca}, \mathrm{Fe}$, and $\mathrm{Mg}$ were measured but only $\mathrm{Al}$ and $\mathrm{Si}$ are discussed detail here. The dissolution extents of $\mathrm{Ca}, \mathrm{Mg}$, and $\mathrm{Fe}$ were lower than that of $\mathrm{Al}$ and $\mathrm{Si}$, however, it is possible that secondary phases of these elements could have precipitated. Discussion regarding $\mathrm{Ca}$, $\mathrm{Mg}$, and Fe dissolution and further discussion of dissolution 
phenomena for the disc milled mine tailings can be found in Perumal et al. [17].

\subsection{Modified $\mathrm{R}^{3}$ test}

The modified $\mathrm{R}^{3}$ test was carried out on the mine tailings in a calcium rich pore solution. SCM and laboratory grade calcium hydroxide were dry mixed in a ratio of $1: 3$ in a plastic container in which $0.5 \mathrm{M} \mathrm{KOH}$ solution was added such that the liquid-to-solid ratio was 0.9 . The materials were hand mixed for four minutes and 6-7 $\mathrm{g}$ of paste was placed in a glass ampoule and loaded into an isothermal calorimeter (TAM Air, TA Instruments) preconditioned at $50 \pm 0.05{ }^{\circ} \mathrm{C}$. The heat release was measured for 10 days. At 10 days, about 30-50 mg sample was taken from the bulk to carry out thermogravimetric analysis (TGA). The temperature was ramped at $10^{\circ} \mathrm{C} /$ minute from ambient temperature to $600^{\circ} \mathrm{C}$ in an inert nitrogen atmosphere. The mass loss in the range of around $380-460{ }^{\circ} \mathrm{C}$ was measured using the tangential method to determine calcium hydroxide content, which was used to quantify SCM calcium hydroxide consumption [36]. The heat release and calcium hydroxide consumption were used as measures of SCM reactivity [25]. Three replicates of one sample were tested and the coefficient of variation (COV) was less than $5 \%$.

\subsection{Tests on cementitious pastes - Isothermal calorimetry}

The mine tailings were used to replace $30 \%$ (by weight) of the OPC in cementitious pastes. The OPC and mine tailings were dry mixed in a plastic container and homogenized. Water was added such that the water-to-cementitious materials ratio $(\mathrm{w} / \mathrm{cm})$ was 0.40 , and the materials were hand mixed for four minutes since the quantities were low for lowspeed mechanical mixing. Hobart mixing and low-speed hand mixing result in broadly similar hydration behavior [37]. Approximately 6-7 $\mathrm{g}$ of the paste was placed in a glass ampoule, sealed, and lowered into the isothermal calorimeter preconditioned at $23 \pm 0.05^{\circ} \mathrm{C}$. Heat release was measured for 7 days.

\subsection{Tests on cementitious pastes - Thermogravimetric analysis}

At 7 days, the pastes were extracted from the isothermal calorimeter, crushed using a mortar and pestle and sieved through a $75-\mu \mathrm{m}$ sieve. About 30-50 mg of the powder was placed on a platinum crucible and heated at $10^{\circ} \mathrm{C} /$ minute up to $600{ }^{\circ} \mathrm{C}$ in an inert nitrogen atmosphere. The mass loss in the range of $380-460{ }^{\circ} \mathrm{C}$ was calculated using the tangential method described in Kim and Olek [36] to obtain the 7-day calcium hydroxide content. Replicate measurements of calcium hydroxide contents for the 7-day pastes showed a COV of less than $5 \%$.

\section{Results and discussion}

\subsection{Effect of milling duration on the particle size distribution and amorphous content}

Fig. 1a shows the reduction of $d_{50}$ with increase in disc milling duration from 1 to 15 minutes. Values of $d_{50}$ after ball milling for 30 minutes are also shown. The $d_{50}$ values of NiCu-B-30 and Qtz-B-30 were $6.2 \mu \mathrm{m}$ and $7.4 \mu \mathrm{m}$ respectively and ranged from $2.8 \mu \mathrm{m}$ (NiCu-D-15) to $5.5 \mu \mathrm{m}$ (NiCu-D-1) for the $\mathrm{NiCu}$ tailings and $3.0 \mu \mathrm{m}$ (Qtz-D-15) to $7.7 \mu \mathrm{m}$ (Qtz-D-1) for the Qtz tailings. Similar trends are observed for $d_{10}$ and $d_{90}$ values, but this data is not shown. The disc milled mine tailings were largely finer than the ball milled mine tailings. After about 8 minutes of disc milling, the fineness did not show a significant reduction.

Fig. 1b shows the increase in amorphous content with increase in milling duration using disc milling. Further details regarding the crystalline phases and phases susceptible to amorphization is presented in [17]. The disc milled mine tailings were more amorphous than the ball milled mine tailings, even when the disc milling duration was 1 minute. The Qtz mine tailings were considerably more amorphous than the $\mathrm{NiCu}$ mine tailings under all conditions. By disc milling the mine tailings for 15 minutes, the amorphous content increased from $2 \%$ to $14 \%$ for the $\mathrm{NiCu}$ tailings and from $14 \%$ to $27 \%$ for the Qtz tailings. The increased amorphous contents are due to mechanochemical activation. Increased milling duration leads to increased interparticle collisions and collisions with the milling media, which results in locally high temperatures due to abrasion. The high temperatures cause localized amorphization on the surface of the particles $[38,39]$. Collision impacts also cause disturbance in the structural stability [17] and defects. The increase in amorphous content with milling duration was not linear. While the initial increase was fairly rapid, there was no appreciable increase in amorphous content when the milling duration was increased from 8 to 15 minutes, similar to changes in fineness with milling duration. The amorphous content increase resulted from amorphization of phases such as clinochlore $\left((\mathrm{Mg}, \mathrm{Fe})_{5} \mathrm{Al}\left(\mathrm{Si}_{3} \mathrm{Al}\right) \mathrm{O}_{10}(\mathrm{OH})_{8}\right)$, anorthite $\left(\mathrm{CaAl}_{2} \mathrm{Si}_{2} \mathrm{O}_{8}\right)$, and siderophyllite $\left(\mathrm{KFe}^{2+}{ }_{2} \mathrm{AlO}_{10}(\mathrm{~F}, \mathrm{OH})_{2}\right)$ [17]. Here, the term amorphous content also encompasses the phases that are strained and show deviations from the traditional sharp peaks for crystalline materials in a diffractogram. Performing quantitative x-ray diffraction on complex multi-phase minerals will lead to some associated error in the determined amorphous contents, but this error should not affect the observed trends.

\subsection{Modified $\mathrm{R}^{3}$ test}

Fig. 2 shows the modified $\mathrm{R}^{3}$ test outputs. The classification boundaries were adapted from literature [22,23]. The ball milled mine tailings were the least reactive among the tested materials even after 30 minutes of ball milling. The heat release and calcium hydroxide consumption values of the ball milled tailings were $15 \mathrm{~J} / \mathrm{g} \mathrm{SCM}$ and $21 \mathrm{~g} / 100 \mathrm{~g} \mathrm{SCM}$, respectively ( $\mathrm{NiCu}$ tailings) and $35 \mathrm{~J} / \mathrm{g} \mathrm{SCM}$ and $59 \mathrm{~g} / 100 \mathrm{~g}$ $\mathrm{SCM}$, respectively (Qtz tailings). These materials appeared to 
be as inert, although the Qtz tailings fell outside of the existing characterization scheme. A detailed discussion of the classification boundaries is presented elsewhere [35].
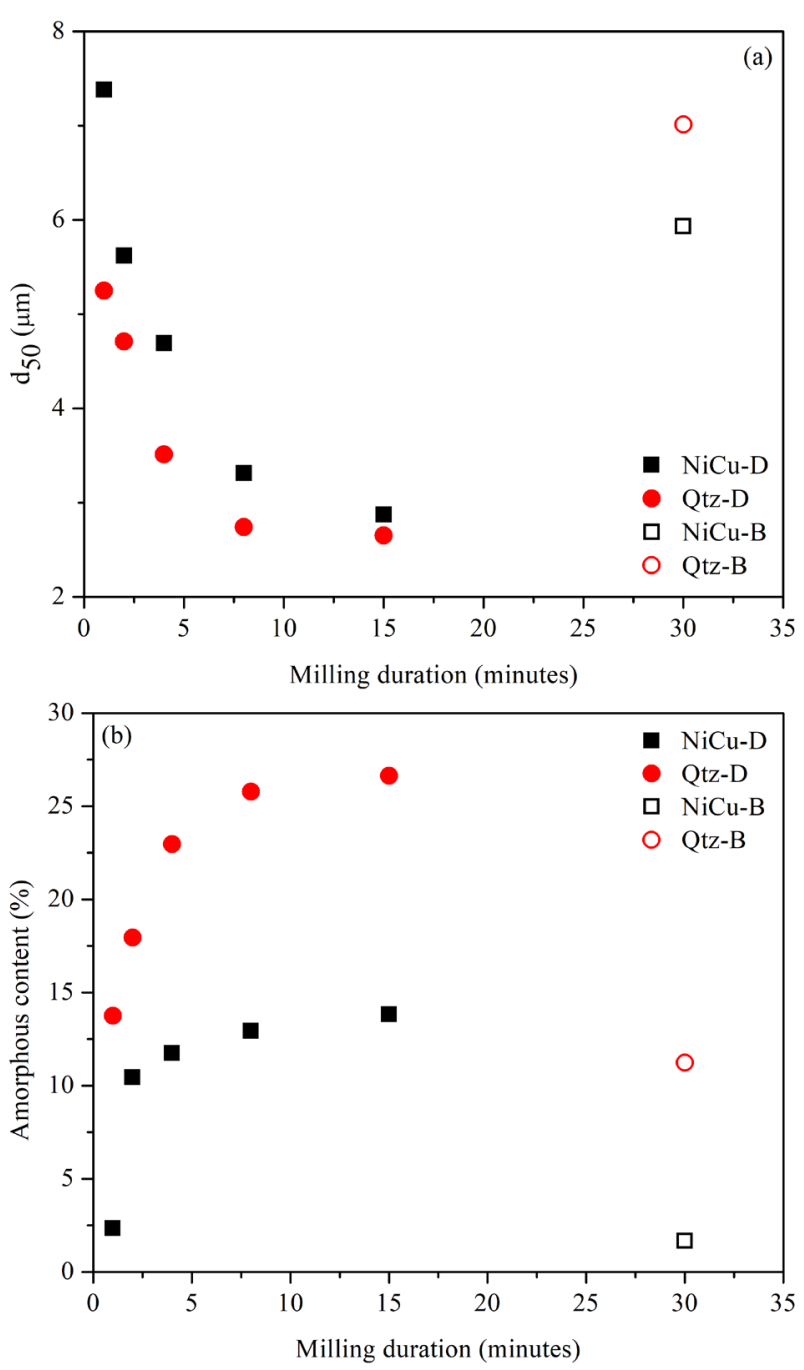

Figure 1. Milling effects on mine tailings - (a) Fineness, (b) Amorphous content.

At relatively smaller $d_{50}$ values and higher amorphous contents, NiCu-D-15, Qtz-D-8, and Qtz-D-15 were classified as pozzolanic, less reactive. The other materials were inert or fell outside of the existing characterization scheme [23]. However, clearly, the reactivity increased with increasing milling duration. There was a moderate correlation with some scatter between the heat release and calcium hydroxide consumption for all SCMs. Similar trends in calcium hydroxide consumption and heat release are unsurprising as the pozzolanic reaction, which releases heat, occurs when calcium hydroxide reacts with the amorphous aluminosilicate portion of the SCMs, at least for pozzolanic materials. However, some differences were evident between the $\mathrm{NiCu}$ and Qtz tailings, with the NiCu tailings appearing to show a greater slope (Fig. 2) when compared to the Qtz tailings, possibly due to differences in $\mathrm{Al}_{2} \mathrm{O}_{3}$ and $\mathrm{MgO}$ contents in the tailings, leading to somewhat different reactions. In further discussion, calcium hydroxide consumption is not discussed; its trends were largely similar to those of the heat release.

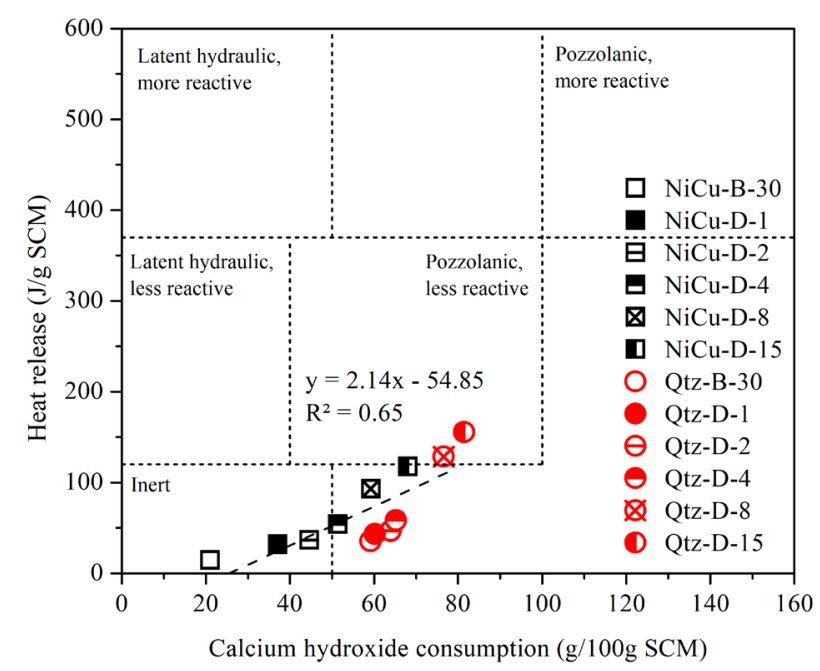

Figure 2. Output of modified $\mathrm{R}^{3}$ test for mine tailings.

\subsection{Effects of SCM amorphous content and fineness on reactivity}

Fig. 3 shows an appearent linear increase of the heat release in the modified $\mathrm{R}^{3}$ test with milling duration, although it may be argued that the reactivity plateaus after 8 minutes of disc milling. Further data is needed to confirm the exact trends. We have shown elsewhere that SCM reactivity increases with the SCM fineness [24]. Here, the effects are due to both increasing fineness and amorphous contents. With increase in milling duration, in addition to increased SCM fineness and amorphous content, there are also increased strains and defects in the crystal structure of the SCMs, which could also result in an increase in the reactivity [17].

Fig. 4a shows that the heat release of disc milled mine tailings in the modified $R^{3}$ test decreased as the $d_{50}$ values increased. As the data was limited, and there appeared to be nonlinearities in the behavior, we only show the points joined by straight line segments. Reductions in fineness below a threshold level (which varies depending on the tailing being considered) had a greater impact on the reactivity than initial reductions. Fig. $4 \mathrm{~b}$ shows the correlation of the heat release in the modified $\mathrm{R}^{3}$ test with the amorphous content. The variation of heat release with amorphous content was nonlinear, possibly bi-linear. The heat release increased significantly when amorphous content was increased beyond a certain threshold, around $10 \%$ for the $\mathrm{NiCu}$ tailings and around 20\% for the Qtz tailings. Interestingly, while the increase in reactivity (Fig. 3) with milling duration appears to be linear, it is in fact driven by two non-linear processes, one driven by fineness, and the other by amorphous content. Accurately separating the impacts of fineness and amorphous content on increasing reactivity was not possible here. Experiments with better controls, including those using sizefractionated materials and materials showing greater values of amorphous content may aid in separating fineness and amorphous content impacts. 
The increased fineness and amorphous content led to an increased release of dissolved aluminosilicates. Increased release of aluminum and silicon in a $6 \mathrm{M} \mathrm{NaOH}$ solution has been reported for these tailings [17]. The increased dissolution resulted in an increase in the extent of the pozzolanic reaction, which consequently caused the increased calcium hydroxide consumption and heat release [40]. Similar effects of increased amorphous content on calcium hydroxide consumption have been reported elsewhere [25].

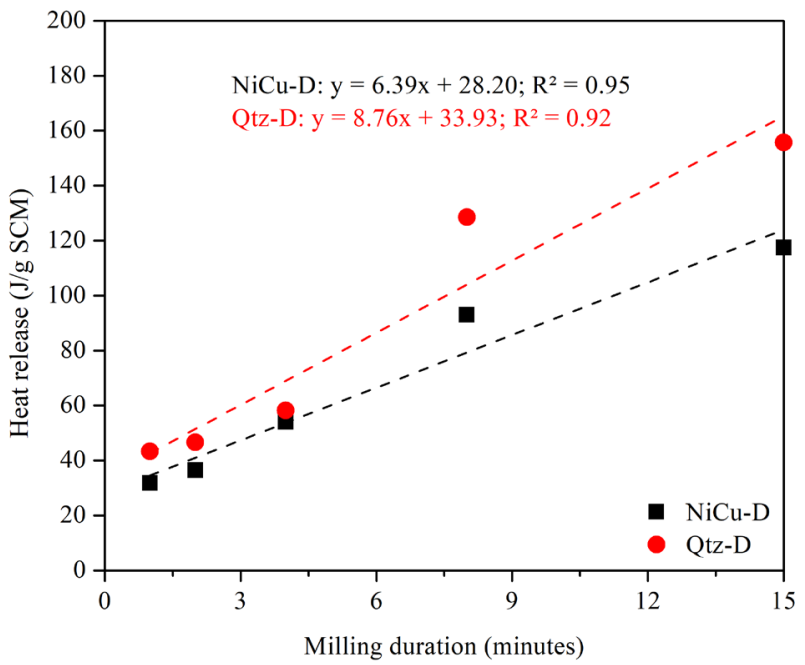

Figure 3. Correlation of heat release in the modified $R^{3}$ test with milling duration.

Fig. $5 a$ and $5 b$ show the correlation between the aluminosilicate species dissolution and the reactivity. The amorphous aluminosilicates present in the SCM were released into the pore solution and the increase in the concentration of these ions in the pore solution was a direct consequence of increased SCM milling duration [17]. Although the alkali dissolution experiments were conducted on a $6 \mathrm{M} \mathrm{NaOH}$ solution, there was strong correlation between silica and alumina dissolution and reactivity, presumably due to higher testing temperature in the modified $\mathrm{R}^{3}$ test, which accelerated the dissolution. Depolymerization of the SCM aluminosilicate network occurs at high $\mathrm{pH}$ values, and it is the interaction of the calcium with the dissolved aluminosilicates that leads to the pozzolanic reaction [41]

The slope of the best fit line in Fig. 5a (heat release vs. aluminum release) was steeper for mixtures with Qtz tailings compared to the mixtures with NiCu tailings, which could be because Qtz mine tailings had higher bulk alumina contents and likely higher amorphous alumina contents after amorphization [17]. Such differences in dissolution for the two tailings were not seen for silica, possibly due to their similar bulk silica contents. The strong correlation between dissolved silica and heat release agrees with studies about silica dissolution during the pozzolanic reaction, which also show the exponential increase in amorphous silicate dissolution with increase in $\mathrm{pH}$ beyond 12.5 [41].
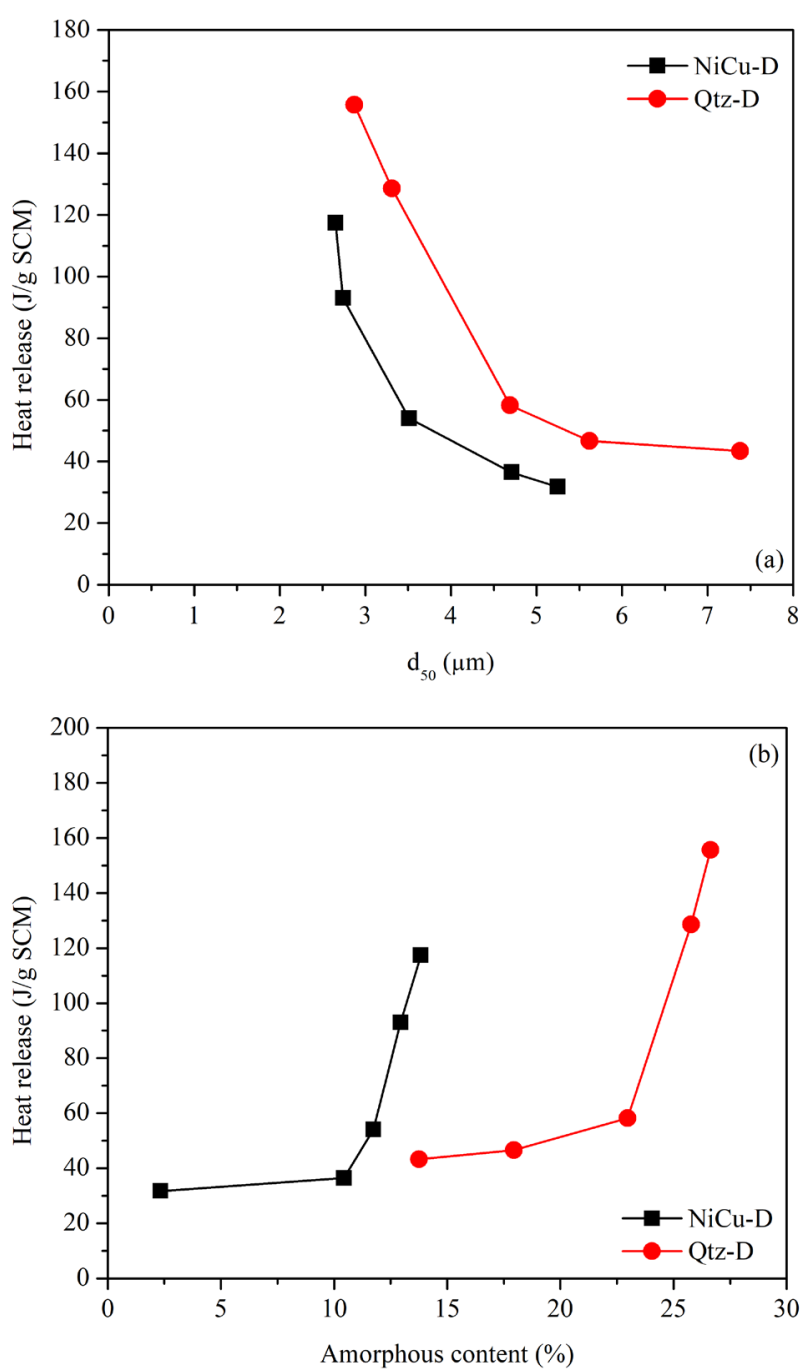

Figure 4. Correlation of heat release in the modified $\mathrm{R}^{3}$ test with - (a) Median particle size, (b) Amorphous content.

Considering that the $\mathrm{pH}$ of the $0.5 \mathrm{M} \mathrm{KOH}$ in the modified $\mathrm{R}^{3}$ test is 13.5 at room temperature, it is possible the modified $R^{3}$ test is driven by similar silicate/aluminosilicate dissolution behavior. At any rate, these studies are among the few that show direct links between SCM dissolution and reactivity in model systems $[40,42,43]$.

\subsection{Energy input, amorphous content, and fineness}

Fig. $6 a$ and $6 \mathrm{~b}$ show the increase in fineness and amorphous content with increase in the input milling energy for disc milled powders, respectively. From the manufacturer data for equipment motor power (ball mill $=0.37 \mathrm{~kW}$, disc mill $=$ $1.5 \mathrm{~kW})$, the amount of input energy for milling was estimated at each milling duration. The changes with milling energy were non-linear and beyond $3600 \mathrm{~J} / \mathrm{g} \mathrm{SCM} \mathrm{(8} \mathrm{minutes} \mathrm{of} \mathrm{disc}$ milling), there was no significant decrease in $d_{50}$ or increase in amorphous content explaining why milling duration over 8 minutes led to a plateau in reactivity (Fig. 3) [44]. 

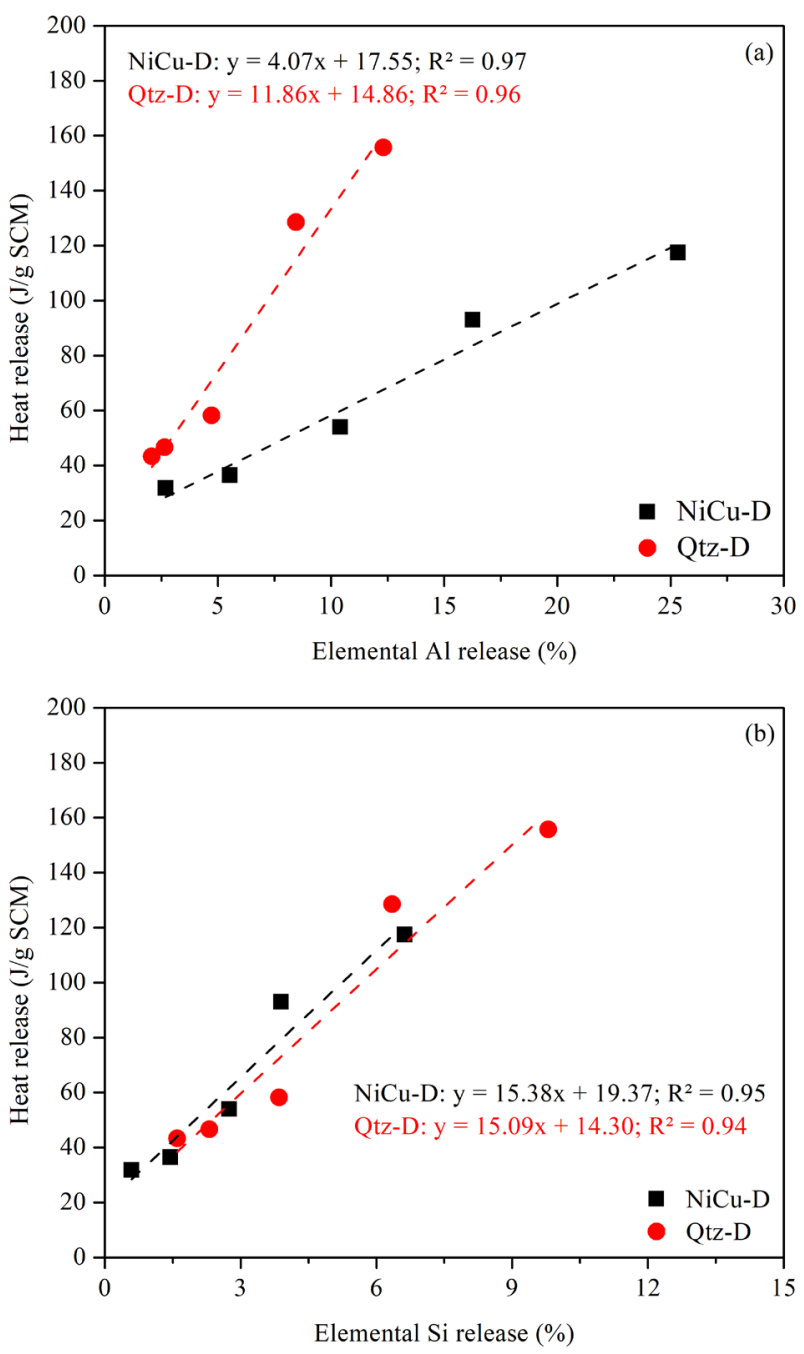

Figure 5. Correlation of elemental release with modified $\mathrm{R}^{3}$ test parameters - (a) Heat release vs. Al release, (b) Heat release vs. Si release.

Ball milling is less efficient due to the lower energy input. Tailings subject to 30 minutes of ball milling consumed energy of $660 \mathrm{~J} / \mathrm{g}$ SCM and resulted in similar fineness and amorphous content but lower reactivity when compared to tailings subjected to 1 minute of disc milling. The material composition and fineness, milling duration, the energy input, and type of milling influenced size reduction and amorphization. These influences are important in beneficiation/activation of alternative SCMs.

\subsection{Tests on cementitious pastes - Isothermal calorimetry and thermogravimetric analysis}

Fig. $7 \mathrm{a}$ and $7 \mathrm{~b}$ show the heat flow and heat release curves of the cementitious pastes. Only four mixtures (NiCu-B-30, Qtz-B-30, NiCu-D-15, and Qtz-D-15) were tested as the materials represented the end points of the reactivity of the mine tailings. The peak heat flow values were similar for the two ball milled mine tailings, around $3.30 \mathrm{~mW} / \mathrm{g}$ cementitious material, a $23 \%$ decrease from the control mixture, indicating that dilution and filler effects dominated at early-ages.
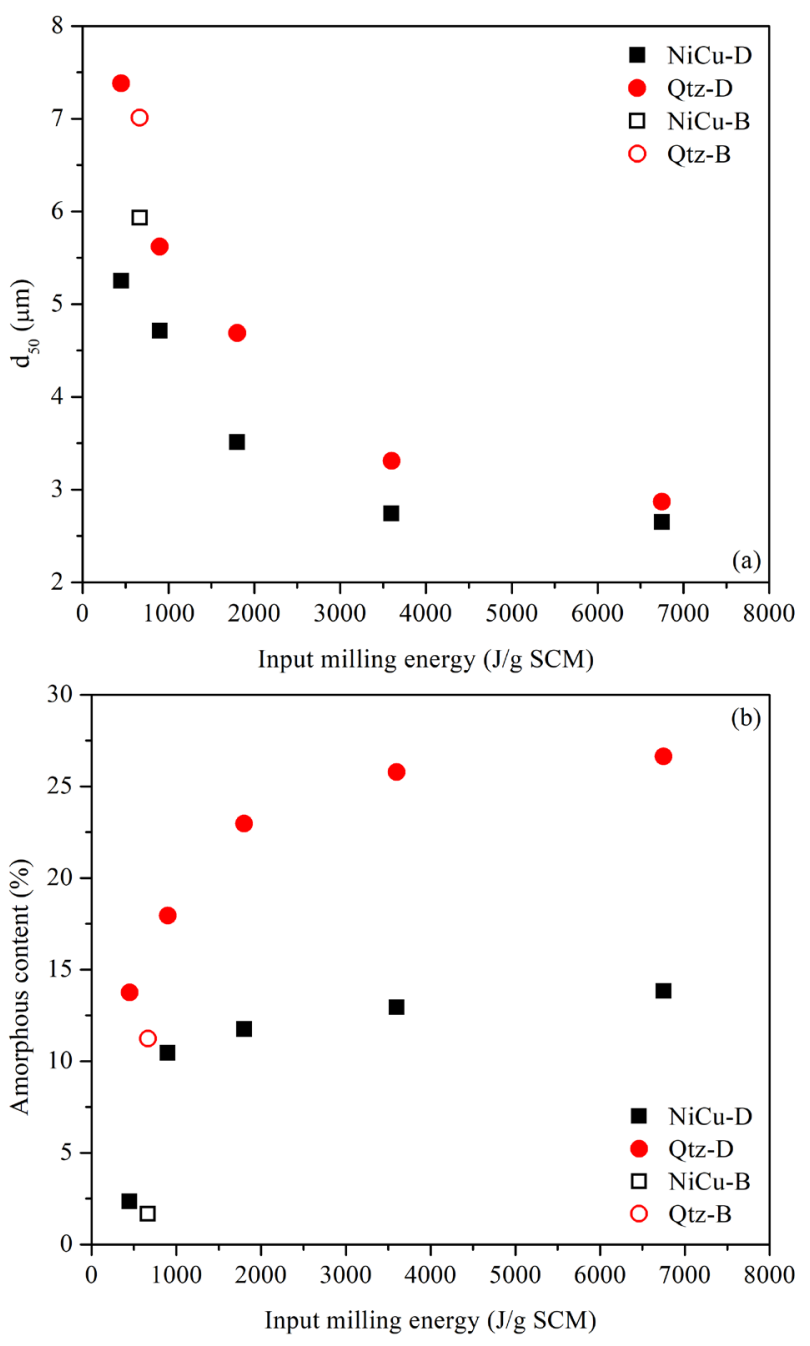

Figure 6. Dependence on input milling energy of - (a) $d_{50}$, (b) Amorphous content.

The corresponding values for NiCu-D-15 and Qtz-D-15 were 3.55 and $3.69 \mathrm{~mW} / \mathrm{g}$ cementitious material respectively, resulting in decreases of $18 \%$ and $14 \%$ from the control mixture values. The disc milled tailings had a higher magnitude of filler effect than the ball milled tailings, presumably due to higher fineness and/or amorphous content. The ball milled tailings reduced the time to peak, whereas the disc milled tailings increased the time to peak. This difference could be due to the release of aluminate ions, which retard the early-age alite hydration $[45,46]$. From dissolution experiments in a $6 \mathrm{M} \mathrm{NaOH}$ solution, the amount of aluminum (by weight of the mine tailings) released into the solution by ball milled tailings ( $\mathrm{NiCu}-\mathrm{B}-30=2.7 \%$ and $\mathrm{Qtz}-\mathrm{B}-30$ $=2.1 \%$ ) was significantly lower than the disc milled samples ( NiCu-D-15 = 25.3\%, Qtz-D-15 = 12.3\%).

Fig. $7 \mathrm{~b}$ shows the 7-day heat release curves. Dilution and filler effects dominated at early ages as expected. The average 7day heat release values for the ball milled samples and disc milled samples were $250 \mathrm{~J} / \mathrm{g}$ cementitious materials and 274 $\mathrm{J} / \mathrm{g}$ cementitious materials respectively. The decrease in 7-day heat release was $20 \%$ for the ball milled tailings and $12 \%$ for 
the disc milled tailings. The filler effect was more pronounced for the more reactive disc milled SCMs $[47,48]$.
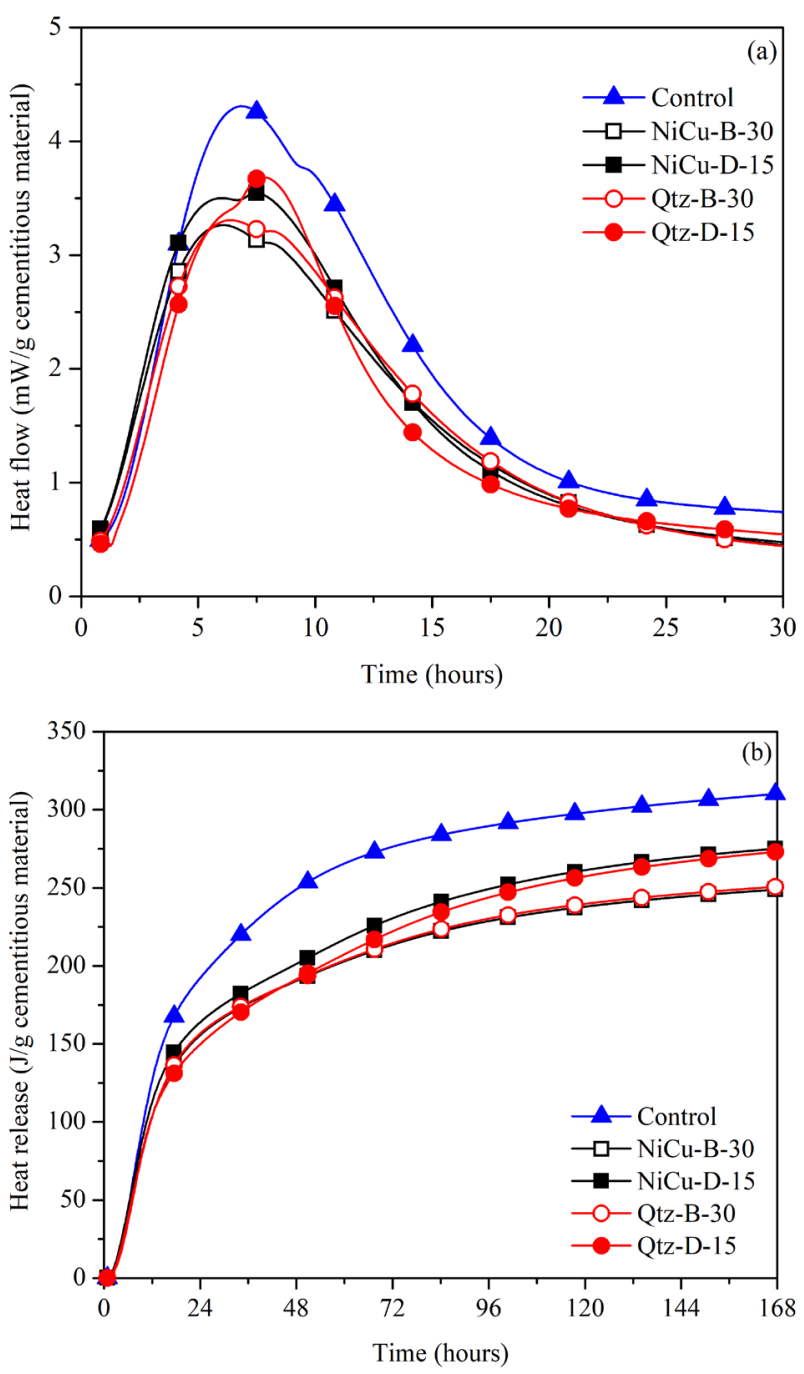

Figure 7. Heat release characteristics of cementitious pastes - (a) Heat flow, (b) Heat release.

Fig. 8 shows the 7-day calcium hydroxide content in the cementitious pastes. Theoretical calcium hydroxide contents based on pure dilution are shown in red. The 7-day calcium hydroxide content ranged from $8.9 \mathrm{~g} / 100 \mathrm{~g}$ cement paste (Qtz-D-15) to $14.3 \mathrm{~g} / 100 \mathrm{~g}$ cement paste (Control). As with heat release, filler and dilution effects appeared to be dominant in all mixtures. However, a small degree of pozzolanic reaction was seen in the NiCu-D-15 and Qtz-D-15 mixtures since the calcium hydroxide content was below the dilution line, with the reduction from the control mixture being $32 \%$ and $38 \%$ respectively. In ball milled tailings, no pozzolanic reaction was apparent. These findings are consistent with those from the modified $\mathrm{R}^{3}$ test, where QtzD-15 had a higher reactivity compared to NiCu-D-15. Similar effects of SCM fineness on pozzolanic reactivity at early ages have been shown in literature [24].

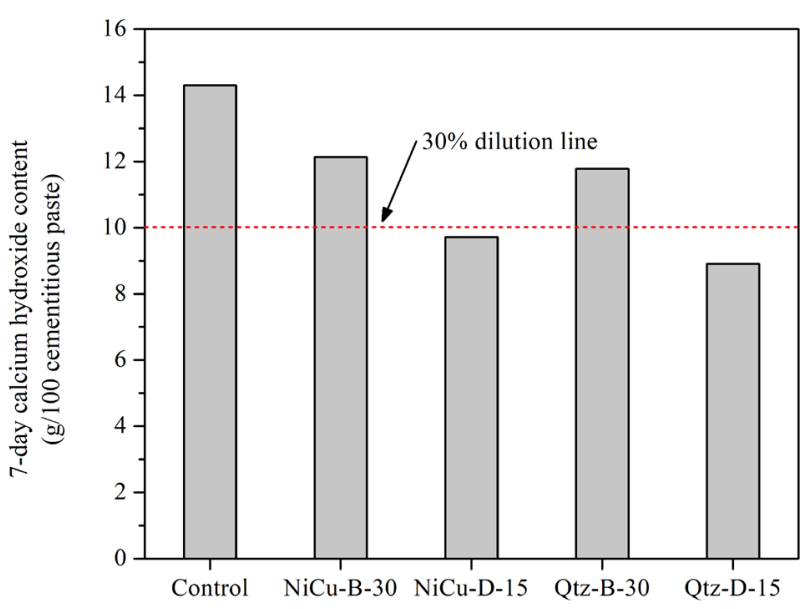

Figure 8. The 7-day calcium hydroxide contents of cementitious pastes.

\section{Conclusions}

Two mine tailings of different compositions were evaluated in this study by milling them using two different methods and different milling durations. The following are the significant conclusions from the study:

1. There was an increase in the amorphous content and fineness in the disc milled samples with increase in milling duration from 1 to 15 minutes. Beyond 8 minutes of milling duration, significant changes in amorphous content and $d_{50}$ were not observed.

2. There was an increase in the heat release and calcium hydroxide consumption in the modified $\mathrm{R}^{3}$ test with increase in milling duration. Ball milled samples are inert, however, disc milling the tailings for longer durations increases SCM reactivity.

3. There were strong correlations between the amorphous content, fineness, and heat release/calcium hydroxide consumption. The correlations showed some non-linearity and a threshold level of fineness and amorphous content over which reactivity increases could be discerned.

4. Strong linear relationships between dissolution and reactivity were demonstrated.

5. The energy input increased with milling duration and resulted in an increase in the amorphous content and a decrease in the fineness.

6. The replacement of OPC with the mine tailings did not significantly affect the hydration behavior at early ages based on 7-day heat release and 7-day calcium hydroxide contents for the different mixtures. Some reactivity in the disc milled mine tailings was evident.

Based on the study, disc milled mine tailings are somewhat reactive and they did not affect the early age hydration, indicating they are potential SCMs. A long-term study regarding hydration and durability for concretes containing such mine tailings as SCMs is warranted. 


\section{Acknowledgements}

The authors would like to thank Titan America for providing the OPC used in the study. The financial support for the Sivakumar Ramanathan through the Dissertation Fellowship awarded by the University of Miami Graduate School is gratefully acknowledged. Priyadharshini Perumal and Mirja Illikainen gratefully acknowledge the financial support received from the project GEOMINS [Grant \#319676: Steps towards the use of mine tailings in geopolymer materials: Reactivity, $\mathrm{CO}_{2}$ Sequestration and Heavy Metal Stabilization] funded by Academy of Finland and the European Union's Horizon 2020 Research and Innovation Programme under the Marie Skłodowska Curie Grant Agreement No [839848].

\section{Authorship statement (CRediT)}

Sivakumar Ramanathan: Methodology, Formal analysis, Investigation, Writing - original draft, Writing - review and editing, Visualization, Funding acquisition.

Priyadarshini Perumal: Methodology, Formal analysis, Investigation, Writing - review and editing.

Mirja Illikainen: Supervision, Resources, Writing - review and editing, Project administration, Funding acquisition.

Prannoy Suraneni: Conceptualization, Supervision, Resources, Writing - review and editing, Project administration.

\section{References}

[1] K.L. Scrivener, V.M. John, E.M. Gartner, Eco-efficient cements: Potential economically viable solutions for a low- $\mathrm{CO}_{2}$ cement-based materials industry. Cem Concr Res (2018) 114: 2-26. https://doi.org/10.1016/j.cemconres.2018.03.015

[2] M.C.G. Juenger, R. Snellings, S.A. Bernal, Supplementary cementitious materials: New sources, characterization, and performance insights Cem Concr Res (2019) 122: 257-273. https://doi.org/10.1016/j.cemconres.2019.05.008

[3] G. Kaladharan, A. Gholizadeh-Vayghan, F. Rajabipour, Review, sampling, and evaluation of landfilled fly ash. ACI Mater J (2019) 116: 113-122. https://doi.org/10.14359/51716750

[4] I. Diaz-Loya, M.C.G. Juenger, S. Seraj, R. Minkara, Extending supplementary cementitious material resources: Reclaimed and remediated fly ash and natural pozzolans. Cem Concr Compos (2019) 101: 44-51. https://doi.org/10.1016/j.cemconcomp.2017.06.011

[5] M. Cheriaf, J.C. Rocha, J. Péra, Pozzolanic properties of pulverized coal combustion bottom ash. Cem Concr Res (1999) 29: 1387-1391. https://doi.org/10.1016/S0008-8846(99)00098-8

[6] C. Jaturapiktakkul, R. Cheerarot, Development of bottom ash as pozzolanic material. J Mater Civ Eng (2003) 15: 48-53. https://doi.org/10.1061/(ASCE)0899-1561(2003)15:1(48)

[7] S. Seraj, R.D. Ferron, M.C.G. Juenger, Calcining natural zeolites to improve their effect on cementitious mixture workability. Cem Concr Res (2016) 85: 102-110. https://doi.org/10.1016/j.cemconres.2016.04.002

[8] Y. Wang, P. Suraneni, Experimental methods to determine the feasibility of steel slags as supplementary cementitious materials. Constr Build Mater (2019) 204: 458-467. https://doi.org/10.1016/j.conbuildmat.2019.01.196

[9] B. Traynor, H. Uvegi, P. Chaunsali, E. Olivetti, Reactivity of crystalline slags in alkaline solution. In: Gaustad G. et al, (Eds) REWAS 2019. The Minerals, Metals \& Materials Series (2019). Springer, Cham. https://doi.org/10.1007/978-3-030-10386-6 21

[10] R. Tixier, R. Devaguptapu, B. Mobasher, The effect of copper slag on the hydration and mechanical properties of cementitious mixtures. Cem Concr Res (1997) 27: 1569-1580. https://doi.org/10.1016/S0008-8846(97)00166-X

[11] E. Vejmelková, M. Keppert, P. Rovnaníková, M. Ondráček, Z. Keršner, R. Černý, Properties of high performance concrete containing fine- ground ceramics as supplementary cementitious material. Cem Concr Compos (2012) 34: 55-61.

https://doi.org/10.1016/i.cemconcomp.2011.09.018

[12] F. Riget, P. Johansen, G. Asmund, Uptake and release of lead and zinc by blue mussels. Experience from transplantation experiments in Greenland. Mar Pol Bul (1997) 34: 805-815. https://doi.org/10.1016/S0025-326X(97)00028-3

[13] M.G. Macklin et. al., The long term fate and environmental significance of contaminant metals released by the January and March 2000 mining tailings dam failures in Maramureş County, upper Tisa Basin, Romania. App Geochem (2003) 18: 241-257. https://doi.org/10.1016/S0883-2927(02)00123-3

[14] K. Perner et. al., Contamination of arctic Fjord sediments by $\mathrm{Pb}-\mathrm{Zn}$ mining at Maarmorilik in central West Greenland. Mar Pol Bul (2010) 60: 1065-1073. https://doi.org/10.1016/j.marpolbul.2010.01.019

[15] A.M.T. Simonsen, S. Solismaa, H.K. Hansen, P.E. Jensen, Evaluation of mine tailings' potential as supplementary cementitious materials based on chemical, mineralogical and physical characteristics. J Was Man (2020) 102: 710-721. https://doi.org/10.1016/j.wasman.2019.11.037

[16] J. Esmaeili, H. Aslani, O. Onuaguluchi, Reuse potentials of copper mine tailings in mortar and concrete composites. J Mater Civ Eng (2020) 32: 04020084 https://doi.org/10.1061/(ASCE)MT.1943-5533.0003145

[17] P. Perumal, H. Niu, J. Kiventerä, P. Kinnunen, M. Illikainen, Upcycling of mechanically treated silicate mine tailings as alkali activated binders. J Min Eng (2020) 158: 106587. https://doi.org/10.1016/j.mineng.2020.106587

[18] S. Ahmari, L. Zhang, Production of eco-friendly bricks from copper mine tailings through geopolymerization. Constr Build Mater (2012) 29: 323-331. https://doi.org/10.1016/j.conbuildmat.2011.10.048

[19] F. Vargas, M. Lopez, Development of a new supplementary cementitious material from the activation of copper tailings: Mechanical performance and analysis of factors. J Clean Prod (2018) 182: 427-436. https://doi.org/10.1016/j.jclepro.2018.01.223

[20] Y.W. Choi, Y.J. Kim, O. Choi, K.M. Lee, M. Lachemi, Utilization of tailings from tungsten mine waste as a substitution material for cement. Constr Build Mater (2009) 23: 2481-2486. https://doi.org/10.1016/j.conbuildmat.2009.02.006

[21] S. Ramanathan, M. Croly, P. Suraneni, Comparison of the effects that supplementary cementitious materials replacement levels have on cementitious paste properties. Cem Concr Compos (2020) 112: 103678. https://doi.org/10.1016/j.cemconcomp.2020.103678

[22] S. Ramanathan, M. Kasaniya, M. Tuen, M.D.A. Thomas, P. Suraneni, Linking reactivity test outputs to properties of cementitious pastes made with supplementary cementitious materials. Cem Concr Compos (2020) 114: 103742. https://doi.org/10.1016/j.cemconcomp.2020.103742

[23] P. Suraneni, A. Hajibabaee, S. Ramanathan, Y. Wang, J. Weiss, New insights from reactivity testing of supplementary cementitious materials. Cem Concr Compos (2019) 103: 331-338. https://doi.org/10.1016/j.cemconcomp.2019.05.017

[24] S. Ramanathan, M. Tuen, P. Suraneni, Influence of supplementary cementitious material fineness on their reactivity in model systems and cementitious pastes. Cem Concr Compos (2021, under review).

[25] J. Skibsted, R. Snellings, Reactivity of supplementary cementitious materials (SCMs) in cement blends. Cem Concr Res (2019) 124: 105799. https://doi.org/10.1016/j.cemconres.2019.105799

[26] M.C.G Juenger, R. Siddique, Recent advances in understanding the role of supplementary cementitious materials in concrete. Cem Con Res (2015) 78: 71-80. https://doi.org/10.1016/j.mineng.2019.106026

[27] ASTM C311/C311M-18, Standard test methods for sampling and testing fly ash or natural pozzolans for use in Portland-cement concrete, ASTM International, West Conshohocken, PA (2018). https://doi.org/10.1520/C0311 C0311M-18

[28] J. Pontes, A. Santos Silva, P. Faria, Evaluation of pozzolanic reactivity of artificial pozzolans. Mater Sci Forum (2012) 730: 433-438. https://doi.org/10.4028/www.scientific.net/MSF.730-732.433

[29] E. Ferraz, S. Andrejkovičová, W. Hajjaji, A.L. Velosa, A.S. Silva, F. Rocha, Pozzolanic activity of metakaolins by the French standard of the modified Chapelle test: A direct methodology. Acta Geodyn Geomater (2015) 12: 289-298. https://doi.org/10.13168/AGG.2015.0026

[30] V.A. Quarcioni, F.F. Chotoli, A.C.V. Coelho, M.A. Cincotto, Indirect and direct Chapelle's methods for the determination of lime consumption 
in pozzolanic materials. IBRACON Struct Mater J (2015) 8: 1-7. https://doi.org/10.1590/S1983-41952015000100002

[31] S. Donatello, M. Tyrer, C.R. Cheeseman, Comparison of test methods to assess pozzolanic activity. Cem Concr Compos (2010) 32: 121-127. https://doi.org/10.1016/j.cemconcomp.2009.10.008

[32] D.P. Bentz, A. Durán-Herrera, D. Galvez-Moreno, Comparison of ASTM C311 strength activity index testing versus testing based on constant volumetric proportions. J ASTM Int (2011) 9: 1-9. https://doi.org/10.1520/JAI104138

[33] R.D. Kalina, S. Al-Shmaisani, D. Ferron, M.C.G. Juenger, False positives in ASTM C618 specifications for natural pozzolans. ACI Mater J (2019) 116: 165-172. https://doi.org/10.14359/51712243

[34] F. Avet, R. Snellings, A.A. Diaz, M.B. Haha, K. Scrivener, Development of a new rapid, relevant and reliable $\left(R^{3}\right)$ test method to evaluate the pozzolanic reactivity of calcined kaolinitic clays. Cem Concr Res (2016) 85: 1-11. https://doi.org/10.1016/j.cemconres.2016.02.015

[35] S. Ramanathan, et al., Reactivity of alternative supplementary cementitious materials. Cem Concr Res (2021, under review).

[36] T. Kim, J. Olek, Effects of sample preparation and interpretation of thermogravimetric curves on calcium hydroxide in hydrated pastes and mortars. Transp Res Rec (2012) 2290: 10-18. https://doi.org/10.3141/2290-02

[37] N. Hosseinzadeh, K. Kosar, S. Ramanthan, P. Suraneni, Operatorinduced variability caused by hand mixing of cement paste - Effects on fresh and hardened properties. Adv Civ Eng Mater (2019) 8: 435450. https://doi.org/10.1520/acem20190029

[38] G. Mertens, R. Snellings, K. Van Balen, B. Bicer-Simsir, P. Verlooyd, J. Elsena, Pozzolanic reactions of common natural zeolites with lime and parameters affecting their reactivity. Cem Concr Res (2009) 39: 233-240. https://doi.org/10.1016/j.cemconres.2008.11.008

[39] K. S. Venkataraman, K. S. Narayanan, Energetics of collision between grinding media in ball mills and mechanochemical effects. Pow Tech (1998) 96: 190-201. https://doi.org/10.1016/S0032-5910(97)03368-8

[40] R. Snellings, Solution-controlled dissolution of supplementary cementitious material glasses at ph 13: The effect of solution composition on glass dissolution rates. J Am Ceram Soc (2013) 96: 2467-2475. https://doi.org/10.1111/jace.12480

[41] C. Shi, R.L. Day, Pozzolanic reaction in the presence of chemical activators: Part II - Reaction products and mechanism. Cem Concr Res (2000) 30: 607-613. https://doi.org/10.1016/S0008-8846(00)00214-3

[42] S. Scherb, M. Köberl, N. Beuntner, K. Thienel, J. Neubauer, Reactivity of metakaolin in alkaline environment: correlation of results from dissolution experiments with xrd quantifications. Mater (2020) 13: 2214. https://doi.org/10.3390/ma13102214

[43] N. Garg, J. Skibsted, Pozzolanic reactivity of a calcined interstratified illite/smectite (70/30) clay. Cem Concr Res (2016) 79: 101-111. https://doi.org/10.1016/j.cemconres.2015.08.006

[44] H. Niu, P. Kinnunen, H. Sreenivasan, E. Adesanya, M. Illikainen, Structural collapse in phlogopite mica-rich mine tailings induced by mechanochemical treatment and implications to alkali activation potential. Min Eng 151: 106331. https://doi.org/10.1016/j.mineng.2020.106331

[45] A. Schöler, B. Lothenbach, F. Winnefeld, M. Ben Haha, M. Zajac, H.M. Ludwig, Early hydration of SCM-blended portland cements: A pore solution and isothermal calorimetry study. Cem Concr Res (2017) 93: 71-82. https://doi.org/10.1016/j.cemconres.2016.11.013

[46] L. Nicoleau, E. Schreiner, A. Nonat, lon-specific effects influencing the dissolution of tricalcium silicate. Cem Concr Res (2014) 59: 118-138. https://doi.org/10.1016/i.cemconres.2014.02.006

[47] E. Berodier, K. Scrivener, Understanding the filler effect on the nucleation and growth of C-S-H. J Am Ceram Soc (2014) 97: 37643773. https://doi.org/10.1111/jace.13177

[48] V. Kocaba, E. Gallucci, K.L. Scrivener, Methods for determination of degree of reaction of slag in blended cement pastes. Cem Concr Res (2012) 42: 511-525

https://doi.org/10.1016/j.cemconres.2011.11.010 